\title{
Helicobacter pylori testing plus eradication was as effective and safe as prompt endoscopy for dyspepsia
}

Lassen AT, Pedersen FM, Bytzer P, et al. Helicobacter pylori test-and-eradicate versus prompt endoscopy for management of dyspeptic patients: a randomised trial. Lancet 2000 Aug 5;356:455-60.

\section{QUESTION: Is Helicobacter pylori testing plus eradication as effective and safe as prompt endoscopy in patients with dyspepsia?}

Design

Randomised (allocation concealed*), unblinded,* controlled trial with 1 year follow up.

\section{Setting}

Primary care clinics in Odense, Denmark.

\section{Patients}

500 patients $\geqslant 18$ years of age (median age 45 y, $54 \%$ women) who had had $\geqslant 2$ weeks of dyspeptic symptoms (pain or discomfort in the epigastrium with or without heartburn, regurgitation, nausea, vomiting, or bloating) with a severity that required treatment or investigation. Exclusion criteria included treatment with ulcer healing drugs in the previous month, bleeding or anaemia, unintentional weight loss $>3 \mathrm{~kg}$, or previous gastric surgery. Follow up was $89 \%$.

\section{Intervention}

At entry, all patients were asked to discontinue any nonsteroidal anti-inflammatory drug (NSAID) use. 250 patients were allocated to $H$ pylori testing plus eradication. In this group, $H$ pylori infected patients received 2 weeks of lansoprazole, $30 \mathrm{mg}$ twice daily; metronidazole, $500 \mathrm{mg}$ 3 times daily; and amoxicillin, $1000 \mathrm{mg}$ twice daily, and were offered endoscopy if symptoms did not improve. For patients who had negative results on $H$ pylori testing, those who had previously used NSAIDs had endoscopy, and those who had reflux symptoms but were not using NSAIDs were treated with a proton pump inhibitor (PPI). 250 patients were allocated to prompt endoscopy and received treatment based on their endoscopic results. Patients with normal endoscopic results received reassurance and lifestyle advice.

\section{Main outcome measures}

Self reported dyspeptic symptoms; gastrointestinal symptoms; overall influence of dyspeptic symptoms; quality of life; symptom improvement; patient satisfaction; general practitioner (GP) visits; sick leave days; and use of endoscopy, PPI, H pylori tests, and eradication treatments.

Sources of funding: Odense University; Clinical Institute; Christenson-Ceson Foundation; A J Andersen and wife Foundation; Lundbeck's Foundation; Wyeth Lederle.

For correspondence Dr A T Lassen, Department of Medical Gastroenterology S, Odense University

Hospital, 5000 Odense C, Denmark. Fax +45 66111328 .

\section{Main results}

141 patients $(28 \%)-64(26 \%)$ in the group that received testing plus eradication and $77(31 \%)$ in the prompt endoscopy group-had $H$ pylori infection. Testing plus eradication and prompt endoscopy did not differ for the median proportion of days without dyspeptic symptoms (0.63 $v 0.67, \mathrm{p}=0.12)$, gastrointestinal symptoms, overall influence of dyspeptic symptoms, quality of life, symptom improvement, GP visits, or sick leave days. More patients who received testing plus eradication were dissatisfied with their treatment than were those who received prompt endoscopy (12\% v 4\%, $\mathrm{p}=0.013)$. Patients who received testing plus eradication had lower per patient means for use of endoscopy $(0.5 v 1.25$, $\mathrm{p}<0.0001)$ and PPI (52.2 $v 58.7, \mathrm{p}=0.03)$ than those who received prompt endoscopy and higher per patient means for use of $H$ pylori tests $(1.13 v 0.14, \mathrm{p}<0.0001)$ and eradication treatments $(0.26 v 0.17, \mathrm{p}=0.009)$.

\section{Conclusion}

Helicobacter pylori testing plus eradication was as effective and safe as prompt endoscopy for the primary care treatment of patients with dyspepsia but had greater patient dissatisfaction.

*See glossary.

\section{COMMENTARY}

In this well done study by Lassen $e t a l$, a non-invasive $H$ pylori test with a treat if positive strategy was compared with prompt endoscopy. This study convincingly showed that no clinically important differences existed between the 2 strategies for most outcomes, including number of days without dyspepsia, severity of symptoms, and quality of life. Another recent randomised trial showed that non-invasive $H$ pylori testing and treatment was superior to and more cost effective than placebo in improving uninvestigated dyspeptic symptoms. ${ }^{1}$ These studies add to the increasing literature that shows the benefits of evaluating patients with dyspepsia for $H$ pylori infection before referral. ${ }^{2}$

Several key aspects of this study by Lassen $e t$ al deserve mention. One aspect was the absence of an upper age limit for inclusion. Furthermore, by excluding patients with alarm symptoms, no patients with cancer were misdiagnosed. Most dyspepsia guidelines recommend endoscopy for patients between 50 and 55 years of age. Another design feature worth noting was that patients with heartburn (even dominant heartburn) were not excluded from the study. This is in contrast to the Rome II dyspepsia definition, which excludes heartburn symptoms. Results were similar in a subset of such patients. ${ }^{3}$

The proportion of dissatisfied patients randomly allocated to the test and treat group was higher than that of the endoscopy group ( $12 \% v 4 \%, \mathrm{p}=0.013)$, although the absolute numbers were small. Reasons for this difference may be the reassuring effect of endoscopy or that patients who were negative for $H$ pylori and without heartburn only received lifestyle advice. Increasing evidence exists that PPIs are superior to placebo in such patients.

Sander J O Veldhuyzen van Zanten, MD, PhD Queen Elizabeth II Health Sciences Center Halifax, Nova Scotia, Canada

1 Chiba N, Veldhuyzen van Zanten SJ, Sinclair P, et al, for the CADET-Hp Study Group. Beneficial effect of $H$.pylori eradication therapy on long term symptom relief in primary care patients with uninvestigated dyspepsia: the Cadet-Hp study [abstract]. Gastroenterology 2000;118:A2390.

2 Veldhuyzen van Zanten SJ, Flook N, Chiba N, et al. An evidence-based approach to the management of uninvestigated dyspepsia in the era of Helicobacter pylori. Canadian dyspepsia working group. CMAJ 2000;162:S3-23.

3 Talley NJ, Stanghellini V, Heading RC, et al. Functional gastroduodenal disorders. Gut 1999;45:II37-42. 